\title{
Transformando el Menosprecio en Reconocimiento. Comunidades Escolares Movilizadas
}

\section{Transforming Contempt into Recognition. Mobilized School Communities}

\author{
Donatila Ferrada * y Miguel Del Pino \\ Centro de Investigación en Educación para la Justicia Social (CIEJUS), Chile \\ Universidad Católica del Maule, Chile
}

\section{DESCRIPTORES:}

Educación comunitaria

Educación formal

Justicia social

Innovación pedagógica

Reconocimiento

\section{RESUMEN :}

El modelo de justicia social de reconocimiento ha adquirido particular connotación en el marco de los movimientos sociales contemporáneos, de forma especial en aquellos colectivos tradicionalmente invisibilizados, como comunidades indígenas, rurales, urbano marginales, entre muchas otras. Enlazador de mundos es un movimiento social chileno que se auto organiza en este tipo de contextos, por medio de aulas comunitarias dialógicas, a fin de superar la infravaloración del patrimonio cultural de estas comunidades en los currícula oficiales. Conocer cómo se organizan estos colectivos para superar las injusticias en estas aulas, resulta de interés. Mediante una investigación acción participativa, se identificaron las formas de injusticia/menosprecio y justicia/ reconocimiento producidas en las dinámicas organizativas que adoptan los colectivos sociales que forman parte de estas aulas comunitarias. Para ello, se constituyeron tres comunidades de investigación en tres escuelas en diversidad de contextos culturales: campesino, minero, mapuce, en diferentes regiones geográficas del país. Los resultados evidencian, por una parte, que las dinámicas organizativas de los colectivos que movilizan las aulas comunitarias, son capaces de generar justicia social atribuible a diferentes formas de reconocimiento, y por otra, que las injusticias identificadas como formas de menosprecio, resultaron ser las gatillantes del proceso transformador dialógico que logra producir la justicia de reconocimiento social.

\section{KEYWORDS:}

Community education

Formal education

Social justice

Pedagogical innovation

Recognition

\section{ABSTRACT:}

The social justice model of recognition has acquired particular connotation in the framework of contemporary social movements, especially in those groups traditionally invisibilized, such as indigenous, rural, and marginal urban communities, among many others. Enlazador de mundos is a Chilean social movement that organizes itself in this type of social contexts, through dialogic community classrooms, in order to overcome the undervaluation of the cultural heritage of these communities in the official curricula. It is of interest to know how these collectives organize themselves to overcome the injustices in these classrooms. Through participatory action research, the forms of injustice/contempt and justice/recognition produced in the organizational dynamics adopted by the social collectives that are part of these community classrooms were identified. For this purpose, three research communities were constituted in three schools in a diversity of cultural contexts: peasant, mining, Mapuche, in different geographical regions of the country. The results show, on one hand, that the organizational dynamics of the collectives that mobilize the community classrooms are capable of generating social justice attributable to different forms of recognition, and on the other hand, that the injustices identified as forms of contempt, turned out to be the triggers of the dialogic transforming process that manages to produce the justice of social recognition.

CÓMO CITAR:

Ferrada, D., Del Pino, M. (2021). Transformando el menosprecio en reconocimiento. Comunidades escolares movilizadas. Revista Internacional de Educación para la Justicia Social, 10(1), 211-225. https://doi.org/10.15366/riejs2021.10.1.013

${ }^{*}$ Contacto: dferrada@ucm.cl

ISSN: 2254-3139

revistas.uam.es/riejs 


\section{Introducción}

Durante el siglo XX, dos corrientes de la pedagogía dialógica han inspirado a numerosas experiencias educativas en diferentes contextos, a saber, la pedagogía dialógica freiriana (Freire, 1970; Freire y Shor, 2008) y la pedagogía dialógica bakhtiana (Abd, 2016; Bakhtin, 1991). Entre ellas están, las descritas por Velasco y Alonso de González (2008): pedagogía comunicativa, instrucción dialógica, investigación dialógica, enseñanza dialógica e instrucción con andamiaje. Y las recopiladas por Ward (1994): pedagogía dialógica estructuralista, constructivista social y posestructuralista. Entre esta diversidad de experiencias de pedagogía dialógica, se encuentra la pedagogía dialógica Enlazando Mundos expresada en aulas comunitarias, promovidas por el movimiento social auto organizado denominado Enlazador de Mundos surgido en Chile en 2005.

Enlazador de Mundos, se caracteriza por convocar a personas altamente sensibilizadas por las profundas situaciones de injusticia social, ancladas al sistema educativo nacional en el marco de un Estado neoliberal consagrado desde la década de los ochenta y vigente hasta hoy. La privatización del sistema educativo favoreció profundas modificaciones en la estructura social del país (Oliva, 2008), tales como la segregación social, racial, sexual, cultural, lingüística, económica, territorial y étnica de la población (Lagos, 2015; Williamson y Flores, 2015). En este contexto, este tipo de injusticias ha sido el foco de atención de Enlazador de mundos, toda vez que ellas, han facilitado la fragmentación cultural entre la escuela y su comunidad (Bengoa, 2009).

Con la finalidad de reconstruir los vínculos entre la escuela y su comunidad, Enlazador de Mundos, organiza colectivos integrados por docentes, estudiantes y una diversidad de miembros de la comunidad local (madres, abuelas/os, artesanas, etc.) en cada una de las escuelas que su suman a este movimiento social. El objetivo central que persiguen es alcanzar procesos de transformación relacional y subjetiva al interior de las aulas de clases. Estas iniciativas adoptan el diálogo en cada una de las interacciones pedagógicas como base del proceso transformador. Con el paso del tiempo, a estas experiencias de transformación se les denominó pedagogía dialógica Enlazando Mundos (Ferrada, 2012). Su expresión en aulas comunitarias, se debe a que incluyen a la diversidad de agentes que participan del movimiento social, quienes aportan sus saberes y experiencias culturales, lingüísticas, territoriales, al proceso educativo (Astorga, 2018; Ferrada, 2020).

Estas aulas comunitarias, denotan un carácter polifónico en términos de la pedagogía dialógica bakhtiana, expresado en decisiones de autoría colectiva de la diversidad de agentes sociales que se apropian del espacio del aula y la escuela, otrora exclusivo de docente y estudiantes (Ferrada, 2012), además de la búsqueda de igualdad de posiciones en términos de la pedagogía freiriana (Ferrada, 2020).

Hoy, a más de 15 años de iniciadas las primeras experiencias de aulas comunitarias, se ha observado que se mantienen en el tiempo sin ningún tipo de apoyos oficiales y/o formales (como recursos financieros o proyectos educativos académicos formales), sino que las personas libremente deciden disponer de sus tiempos, sus experiencias e incluso de sus propios recursos para dar vida a las aulas comunitarias. Esta disposición, va más allá de tener hijos o hijas en la escuela, es decir, se trata de un compromiso que permanece en el tiempo, lo cual podría estar indicando que estas experiencias impactan fuertemente la subjetividad y relaciones de sus integrantes. De acuerdo con investigaciones previas (Astorga, 2018; Ferrada, 2020; George-Nascimento, 2015) la igualdad educativa como utopía, la legitimidad del saber experiencial en el currículum escolar y la colaboración, resultan ser características centrales en el proyecto transformador de estas aulas dialógicas.

Pero ¿qué moviliza a los colectivos a generar y mantener en el tiempo estos proyectos transformadores? Se ha observado que, cada vez que los colectivos (docentes, escolares, madres, abuelas, artesanas, etc.) inician sus procesos de auto organización para movilizar la transformación educativa decidida por ellos/ as mismos/as, emergen voces exponiendo sensaciones de injusticias expresadas en experiencias de exclusión y discriminación tanto de sus propias características individuales como de la cultura de la que provienen, como justificación de su ausencia previa de participación y compromiso con la escuela de sus hijos e hijas. Esto, podría estar revelando que los sentimientos de menosprecio movilizarían a estos colectivos, por consiguiente, en términos de teoría de justicia social, estaríamos frente a modelos de reconocimiento (Fraser, 2008, 2018; Honneth, 1997, 2018; Taylor, 1993). 
Si lo anterior es así ¿cuáles son las dinámicas organizativas que estos colectivos problematizan? y ¿qué les permite el funcionamiento a lo largo del tiempo? En todas las dinámicas organizativas que van creando estas comunidades auto organizadas, descansan procesos de subjetividad anclados a relaciones entre quienes comparten estas experiencias. Nuestros supuestos son que, estos aspectos constituyen las bases que sostienen estos colectivos que buscan transformar las situaciones de exclusión, discriminación, etc., que les abruman, pero que son capaces de movilizarse para superarlas. Desde este análisis, esta investigación problematiza sobre ¿cuáles son las dinámicas organizativas que caracterizan estas experiencias dialógicas? y de todas ellas, ¿cuáles pueden identificarse como situaciones de injusticia/menosprecio y cuáles de justicia/reconocimiento?

Desde esta problematización, esta investigación busca identificar las formas de injusticia/menosprecio y justicia/reconocimiento producidas en las dinámicas organizativas que adoptan los colectivos sociales que conforman las aulas comunitarias propias de la pedagogía dialógica Enlazando Mundos.

\section{Revisión de la literatura}

La literatura contemporánea, expone un amplio debate en torno a la idea de reconocimiento como teoría de la justicia social, sus principales representantes, sin duda son Fraser (2008, 2018), Honneth (1997, 2011, 2018, 2019) y Taylor (1993). De acuerdo con Fraser (2008), el reconocimiento -es una de las tres dimensiones junto a la redistribución y la representación que propone como modelo de justicia social-, abarca a las injusticias culturales enraizadas en patrones sociales de representación, interpretación y comunicación de la cultura dominante que se reflejan en invisibilización, dominación cultural y falta de respeto para los grupos no pertenecientes a ella. Éstas injusticias descansan en que "en cada una de estas situaciones, a determinados actores sociales se les impide participar en un plano de igualdad con los demás en la interacción social" (p. 118). A este respecto afirma "la solución a la injusticia es un cambio cultural o simbólico", cuestión que podría alcanzarse mediante el principio normativo de paridad participativa, esto es, logrando igualar el estatus cultural de las personas y sus colectividades de tal forma que puedan participar en igualdad para conseguir la estima social (Fraser, 2018).

Para Honneth (2018), el reconocimiento forma parte constitutiva de la estructura de la integración social y determina el desarrollo de la identidad personal de los sujetos a partir de "unas formas fiables de reconocimiento mutuo, cuyas insuficiencias y déficits están vinculadas siempre a las sensaciones de reconocimiento erróneo, que a su vez pueden considerarse como motor de cambio social” (p. 182). Para este autor, las esferas diferenciadas de reconocimiento obedecen a tres principios normativos: el amor, la igualdad de trato y el mérito social. De esta forma, las interacciones sociales basadas en el amor permiten a los sujetos comprenderse con necesidades propias, generando así, la autoconfianza. Por su parte, las interacciones sociales basadas en la igualdad de trato, permite a los sujetos comprenderse con la misma autonomía que los demás, generando así el autorrespeto. Y las interacciones sociales basadas en el mérito, permite a los sujetos comprenderse con habilidades y talentos valiosos para la sociedad, generando así, la estima social. Cuando estas formas de reconocimiento son fallidas o erróneas, entonces emergen los sentimientos de injusticia en directa relación con estos principios normativos, que se manifiestan a través de los conflictos sociales en los diversos ámbitos culturales, sexuales, étnicos, etc., por parte de las personas y/o colectivos, configurándose asíla sociedad del desprecio (Honneth, 2011). El menosprecio, se manifiesta a través de las experiencias intuitivas producidas en la interacción social y percibidas como violaciones de la propia dignidad, honor e integridad de las personas y sus comunidades (Vázquez, 2008), es decir, cuando el reconocimiento es fallido en una o más de las esferas del reconocimiento. Cuando se afecta la esfera del amor, con la falta de afecto, cuidado y/o protección en las personas, se trastoca la construcción de la confianza en sí mismo. Cuando se afecta la igualdad de trato, con la desposesión de derechos y exclusión se impide el desarrollo de autonomía de las personas para comprenderse con los mismos derechos que los demás. Y cuando se desvaloriza el mérito que portan las personas, por considerar que sus habilidades y talentos en la estructura de la división del trabajo no son o son poco valiosos para la sociedad, se afecta la estima social (Honneth, 2018).

Por su parte Taylor (1993), acuña el concepto de "política del reconocimiento" o "política de la diferencia" que considera las diferencias culturales y apuesta por preservar las comunidades en las que se viven esos rasgos diferenciadores, para lo cual se requiere atribuir derechos diferentes a comunidades culturales 
diferentes. Por lo cual, se le asocia a este autor, con la defensa del multiculturalismo, pues "la política de la dignidad igualitaria es, en realidad, el reflejo de una cultura hegemónica. Así, según resulta, sólo las culturas minoritarias o suprimidas son constreñidas a asumir una forma que les es ajena" (Taylor, 1993, p. 67). De esta forma, este autor, comparte que "el multiculturalismo es hoy una realidad que se extiende por el mundo y que exige una política abierta al reconocimiento de las diferenciaciones culturales y de las metas colectivas" (Donoso, 2003, p. 18).

Claro es que cada uno de estos autores asientan sus propuestas sobre el reconocimiento de forma diferenciada. Mientas Taylor (1993), aboga por un reconocimiento de las diferencias culturales a través de políticas identitarias que mantengan las diferencias intactas porque son valiosas en sí mismas, Fraser (2008) lo hace por medio de una igualación en el estatus entre todas las culturas desde la paridad participativa de los miembros de todas ellas. Para Honneth (2018) se requiere de una reconstrucción de las relaciones sociales en cuales se desarrolla la identidad personal, para ello, es necesario que cada miembro afectado por un reconocimiento fallido pueda experienciar en el espacio público una reparación a éste, pues define "reconocer" como un acto público, a diferencia de "conocer", que es un acto privado, es decir, las y los integrantes de las culturas deben percibirse validadas en todos los espacios en los que interactúan.

Todas estas teorías de justicia social sobre el reconocimiento resultan de sumo interés, para el análisis de la experiencia de aulas comunitarias de pedagogía dialógica Enlazando Mundos, sobre todo porque son proyectos que construyen colectivos auto organizados, que surgen a propósito de las situaciones de negación, invisibilidad de personas y colectivos, referidas a la cultura campesina, cultura minera, cultura indígena, entre otras, y que se proponen transformar.

Estudios previos (Ferrada, 2012, 2020), muestran que estos colectivos logran transformar el aula por medio de proyectos con sentido colectivo, con la finalidad de alcanzar igualdad educativa para la totalidad del estudiantado, cuestión que podría encontrar relación con el principio de paridad participativa para romper las jerarquías de estatus en términos de Fraser (2008); así también, estos colectivos transforman el proceso de enseñanza-aprendizaje, asumiendo simultáneamente el rol de enseñar y aprender, lo que podría corresponderse con la idea de establecer relaciones sociales de reconocimiento recíproco en palabras de Honneth (2011).

En este contexto, las dinámicas de organización que dan vida a estas aulas comunitarias dialógicas, asumen que la escuela "es una organización que trabaja con personas, entre personas y para personas" (Velásquez et al., 2006, p. 100) democratizando así sus interacciones sociales. En un contexto social comunitario, la multiplicidad de relaciones entre actuantes resulta común (López, 2005; Velásquez et al., 2006). Desde esta comprensión, las aulas que desarrollan una pedagogía dialógica Enlazando Mundos, coinciden en que la participación comunitaria releva la interdependencia entre múltiples actuantes sociales para alcanzar los propósitos educativos (Herrera, 2016), como una estrategia para romper con el modelo tradicional de organización escolar, que concibe estas interacciones del componente humano como elementos aislados e independientes (Álvarez, 2000).

\section{Método}

En correspondencia con las características de las aulas comunitarias, el estudio considera la participación de los propios agentes de estas transformaciones en las escuelas (docentes, estudiantes, madres, abuelas, estudiantes universitarios, etc., más investigadores). Con este fin, se optó por el paradigma participativo de investigación (Gayá Wicks y Reason 2009; Guba y Lincoln 2012; Heron y Reason, 1997) y por el enfoque metodológico denominado investigación dialógica-kishu kimkelay ta che (Ferrada y Del Pino, 2018; Ferrada, 2017; Ferrada et al., 2014). Esta metodología, tiene como eje principal la igualdad de posiciones entre participantes e investigadores, partiendo del supuesto que cada quien aporta su propia experticia, ya sea dada por la propia experiencia de cada uno y/o por la formación académica que porta, teniendo presente que sus aportes pueden ser susceptibles de críticas por los demás participantes (Habermas, 1987).

Este enfoque metodológico requiere de la conformación de comunidades de investigación, las cuales deciden qué, para qué y cómo investigar. Para ello, y dado que, a la fecha, la experiencia de aulas comunitarias con pedagogía dialógica Enlazando Mundos en Chile se extiende a 9 regiones del país (de 16 en total), cuestión que implica una amplia diferencia de los contextos de cada una y de las motivaciones iniciales 
para la transformación. No obstante, todas estas experiencias tienen en común que se organizan en torno al movimiento social Enlazador de Mundos, lo que las articula a nivel nacional a través de encuentros anuales en que comparten sus especificidades. Es en este contexto, donde los autores de este trabajo se integran en algunas de estas experiencias a pedido de los propios colectivos que las movilizan y que solicitan colaboración para profundizar en sus propios procesos de transformación. Así, se decide conformar 3 comunidades de investigación durante el periodo escolar 2018-2020 (marzo-diciembre), que para efectos de este estudio se denominan comunidad campesina, minera y mapuce (Cuadro 1).

Cuadro 1

Características de las comunidades de investigación (CI)

\begin{tabular}{|c|c|c|}
\hline $\bar{J}$ & $\begin{array}{l}\text { Origen del aula comunitaria e inicio } \\
\text { de la experiencia de transformación }\end{array}$ & Integrantes de la CI \\
\hline 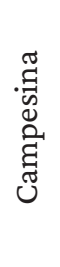 & $\begin{array}{l}\text { Inicia su proceso de transformación en } 2015 \text {, a propósito de una pro- } \\
\text { funda fragmentación entre la escuela y su comunidad por quiebre de } \\
\text { relaciones de confianza que se reflejó en una bajísima matrícula (1 } \\
\text { estudiante) que la expuso al cierre. Posterior a esta situación, la escuela } \\
\text { reconstruyó las relaciones con su comunidad y recuperó la matrícula } \\
\text { escolar e incluyó en el aula comunitaria entre otros, a madres, abuelas, } \\
\text { artesanas y obreros agrícolas. }\end{array}$ & $\begin{array}{l}16 \text { personas: } 1 \text { docente, } 3 \text { abue- } \\
\text { las, } 5 \text { estudiantes, } 3 \text { artesanas, } 1 \\
\text { personal técnico, } 1 \text { asistente de } \\
\text { aula y } 2 \text { investigadores (autores } \\
\text { de este artículo). }\end{array}$ \\
\hline 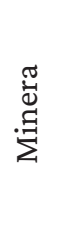 & $\begin{array}{l}\text { Inicia su proceso de transformación en } 2009 \text {, en respuesta a la pre- } \\
\text { sión ejercida sobre los docentes desde el Ministerio de Educación, para } \\
\text { obtener altos rendimientos en la prueba estandarizada nacional. Estas } \\
\text { exigencias, hacen que esta comunidad se auto organice construyendo un } \\
\text { aula comunitaria que se mantiene hasta el presente y que incluye en su } \\
\text { trabajo cotidiano a madres y abuelas de la comunidad }\end{array}$ & $\begin{array}{l}15 \text { personas: } 1 \text { docente, } 1 \\
\text { asistente de aula, } 1 \text { auxiliar, } \\
6 \text { madres, } 4 \text { estudiantes, } 2 \\
\text { investigadores (autores de este } \\
\text { artículo). }\end{array}$ \\
\hline 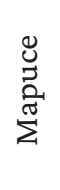 & $\begin{array}{l}\text { Inicia su proceso de transformación en } 2010 \text {, a propósito de la recupera- } \\
\text { ción de la escuela que realiza la comunidad (previamente administrada } \\
\text { por la Iglesia Católica) y la posterior oficialización de planes y programas } \\
\text { mapuce que recogen la cosmovisión del pueblo mapuce, para ello requie- } \\
\text { ren de una pedagogía comunitaria y optan por las aulas comunitarias. }\end{array}$ & $\begin{array}{l}10 \text { personas: } 5 \text { docentes mapu- } \\
\text { ce, } 3 \text { estudiantes de pedagogía, } \\
2 \text { investigadores (autores de } \\
\text { este artículo). }\end{array}$ \\
\hline
\end{tabular}

Nota. Elaboración propia.

La comunidad campesina, se ubica en una escuela de la región del Maule, en la zona central del país, en un aula comunitaria en contexto socio-cultural campesino-rural de una escuela municipal (pública), unidocente, con aula multigrado de $1^{\circ}$ a $6^{\circ}$ año básico, con una matrícula de 10 estudiantes. Sus estudiantes provienen de familias -según indicadores usados por el Estado- altamente vulnerables (Índice de Vulnerabilidad Escolar [IVE] =100\%) (JUNAEB, 2020) y que tienen como actividad productiva la pequeña agricultura. Por su parte, la comunidad minera, se ubica en una escuela de la región del Biobío, en la zona centro sur del país, en un aula comunitaria en contexto socio-cultural minero de una escuela municipal (pública), altamente urbanizada, con una matrícula de 800 estudiantes de $1^{\circ}$ a $8^{\circ}$ de enseñanza básica. Sus estudiantes provienen de familias caracterizadas como altamente vulnerables (IVE $=95 \%$ ) (JUNAEB, 2020), cuya actividad productiva principal durante décadas fue la explotación del carbón, hoy en día discontinuada, pero en términos culturales, pervive esta cultura. Finalmente, la comunidad mapuce, se ubica en una escuela de la región de La Araucanía, zona sur del país, con alta presencia de pueblo mapuce (33\%). Éste pueblo representa $80 \%$ del total de la población indígena presente en el país, (13\% de la población nacional) (INE, 2020). Se trata de una escuela caracterizada como altamente vulnerable (IVE = 100\%) (JUNAEB, 2020), con una matrícula de 49 estudiantes mapuce y 5 docentes, todos bilingües.

Las tres comunidades de investigación, optaron por los procedimientos de construcción del conocimiento propios de la metodología dialógica-kishu kimkelay ta che, conversación dialógica, diálogos colectivos, y az kintun. La conversación dialógica (CD), es entendida como "un diálogo situado entre dos personas, que se consideran clave para la profundización de una temática” (Ferrada, 2017). Los diálogos colectivos (DC), son encuentros dialógicos entre diversas personas para hablar sobre una temática y generar una interpretación colectiva. En cambio, az kintun (AK), consiste en interpretar situaciones, acciones, vivencias, sueños, experiencias, relatos, orales, escritos y audiovisuales de la temática de estudio (Ferrada y Del Pino, 2018). De allí, que az kintun fue usado para el análisis de filmaciones de video de dos tipos de 
actividades, a saber, preparación y desarrollo de las clases. Estos procedimientos, se realizaron durante los años del estudio. Por cada comunidad de investigación, se realizaron 20 conversaciones dialógicas, 10 diálogos colectivos y 15 videos de preparación de clases y 15 videos de desarrollo de clases y 15 az kintun, todas estas instancias fueron grabadas y transcritas. También cabe señalar que se realizaron todos los resguardos éticos a través de consentimientos y asentimientos informados.

El análisis de la información se realizó con apoyo del software de datos cualitativos NVIVO 12 Plus, construyendo nodos temáticos que permitieron organizar los datos en tres categorías matrices, que resultaron comunes en las tres aulas comunitarias estudiadas, a saber: a) articulación de redes: redes entre personas $y / o$ instituciones que colaboran en la escuela; $b$ ) formas de trabajo en aula: tipo de relaciones entre las personas, y de roles y prácticas que ingresan al trabajo pedagógico; y, c) territorialidad escolar: concepto de espacio educativo que manejan las personas que participan en el aula. Posteriormente, cada comunidad de investigación, caracterizó ese conocimiento en dos tipos: a) conocimiento transformador, aquellos conocimientos producto del trabajo comunitario que reportan un avance notorio respecto de las condiciones iniciales a la transformación; $y, b$ ) conocimiento exclusor, aquellos conocimientos pre-existentes o nuevos que se constituyen en obstáculos para la transformación que se persigue. De esta forma, se consideró al conocimiento exclusor como insumo para identificar las situaciones de injusticia/ menosprecio dadas por: a) invisibilización de redes entre personas e instituciones representativas de la propia cultura del alumnado $\mathrm{u}$ otras culturas distintas de la cultura escolar; $\mathrm{b}$ ) sometimiento a patrones de interpretación y comunicación exclusivos de la cultura escolar oficial, y; c) menoscabo o mal trato en las interacciones sociales que mantienen las personas durante el proceso educativo. En cambio, el conocimiento transformador fue el insumo para identificar las formas de justicia/reconocimiento dadas por: a) visibilización de redes entre personas e instituciones representativas de la propia cultura del alumnado u otras culturas distintas de la cultura escolar; b) legitimación de patrones de interpretación de la cultura del alumnado y de otras distintas a la cultura escolar oficial, y; c) dignidad e igualdad de trato en las interacciones sociales que mantienen las personas durante el proceso educativo (Figura 1).

Figura 1

Matriz metodológica de categorías

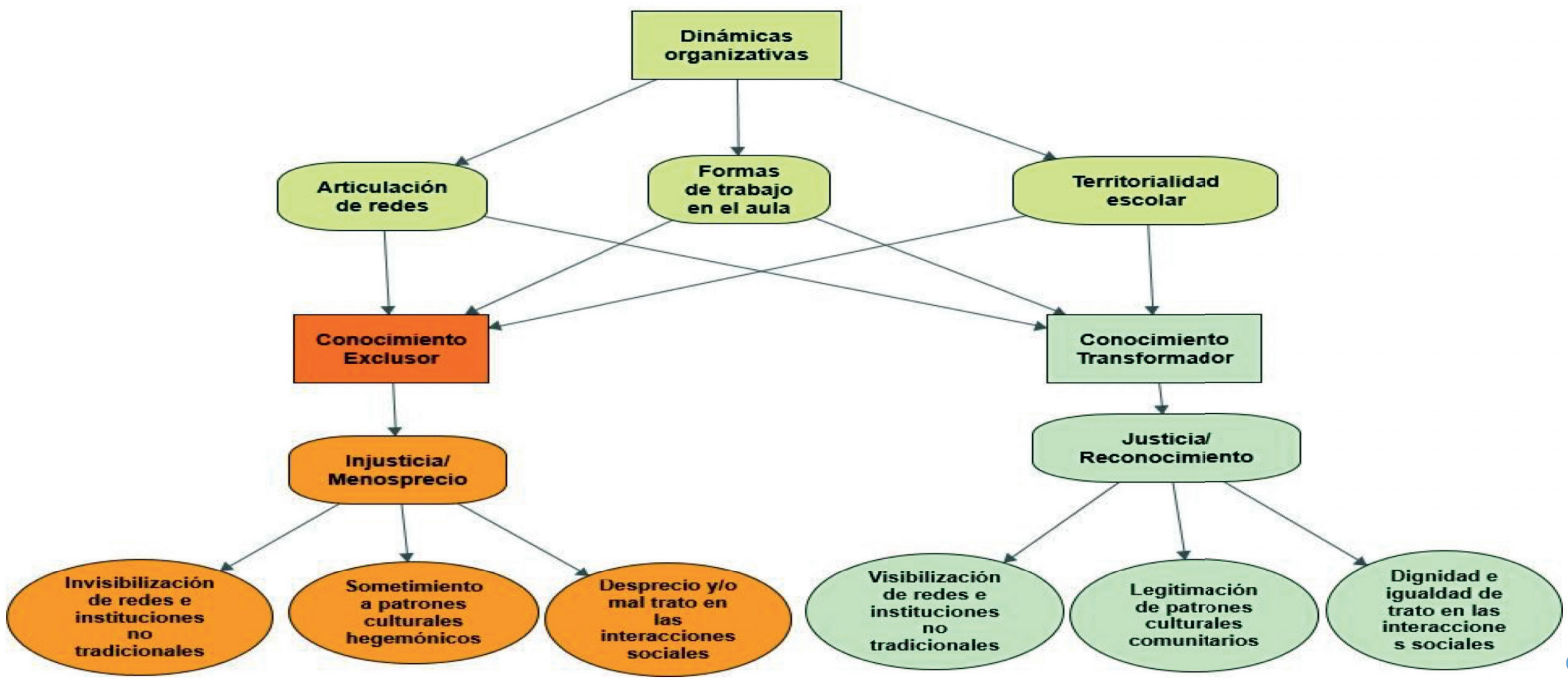

\section{Resultados}

Todas las comunidades de investigación (campesina, minera y mapuce) lograron distinguir dos momentos claves en el proceso de transformación de las aulas: uno, previo a la conformación del aula comunitaria y otro, durante el desarrollo de la misma. 


\subsection{Comunidad campesina. Menosprecio y reconocimiento en dinámicas orga- nizativas}

\subsubsection{Articulación de redes}

La comunidad campesina, previo a la conformación del aula comunitaria, constató la ausencia de redes entre personas e instituciones. Éste ámbito fue categorizado como conocimiento exclusor, por consiguiente, indicador de situaciones de menosprecio. Ejemplos que grafican el menosprecio son: “...aquí la escuela funcionaba a espaldas de la familia...la escuela no tenía ninguna relación con otras instituciones de la comunidad, como la junta de vecinos, la municipalidad, las agrupaciones de artesanos, con nadie, solo la profesora y su estudiante” (DC, 7 y 9), así invisibilizaba a las organizaciones de colectivos e instituciones presentes tanto en la comunidad como en el propio sistema educativo local que pueden colaborar en la escuela. La ausencia de redes somete al estudiantado a patrones interpretativos exclusivos de la organización escolar, produciéndose un menosprecio, dado por el despojo de sus propias formas de organización como válidas para contribuir en la escuela.

En cambio, la comunidad campesina, posterior a la conformación del aula comunitaria, constata la presencia de redes entre personas e instituciones, ámbito categorizado como conocimiento transformador, por consiguiente, insumo para identificar el reconocimiento. Ejemplos que lo grafican son: “..aquí trabaja coordinadamente el equipo interdisciplinar, la nutricionista, el profesor de educación física, el microcentro, la municipalidad, los museos...las abuelitas están aquí, las artesanas, las mamás" (CD, Docente), así se visibiliza la representación tanto de personas como de las organizaciones colectivas que colaboran en la escuela: “...mostramos cómo nos organizamos nosotros, para hacer nuestras cosas aquí en el campo y eso también sirve a la escuela” (CD, Abuela 2), “...yo enseño el arte de la greda...se necesita organización para hacerlo, con el que conoce la tierra, con el que sabe de filtrado...” (CD, Artesana), de esta forma, se rompe con la dominación de un solo modelo organizativo, el escolar, en tanto patrón hegemónico de interpretación, y en su reemplazo, se amplía a la diversidad de formas de organización presentes en toda la comunidad. Esta incorporación de diversidad de redes dignifica a sus contribuyentes al validar sus prácticas organizativas como valiosas para la escuela.

\subsubsection{Formas de trabajo en el aula}

La comunidad campesina, previo al aula comunitaria, constata que las formas de trabajo en el aula, consisten en clases frontales y expositivas con prácticas descontextualizadas y las categoriza como conocimiento exclusor, en tanto indicadores de menosprecio. Algunas voces que lo ejemplifican son: “...todas las clases las dictaba la profesora, no se podía ni preguntar porque no le gustaba” (CD, Estudiante 4), "aquí se enseñaba lo que venía solo en el libro de clase, no se consideraban las prácticas, el saber, las experiencias de los estudiantes” (CD, Docente). Estos ámbitos fueron categorizados como formas de menosprecio, pues se observaba, la invisibilización del alumnado, la sujeción del mismo a la figura de poder y control del docente, el sometimiento interpretativo de los saberes curriculares oficiales impuestos como únicos conocimientos válidos, y el despojo de roles y prácticas culturales propias de la cultura de las y los estudiantes.

En cambio, la comunidad campesina, posterior a la conformación del aula comunitaria, constató un conjunto prácticas que categoriza como conocimiento transformador, por tanto, indicadores de reconocimiento: 1) prácticas propias de la cultura campesina, tales como: “...las recetas de comidas que se hacen en el campo, con productos de la tierra...el cuidado de animales es una práctica incorporada ... cuentos campesinos relatados por abuelos y abuelas en el aula” (AK, 6), así se manifiestan procesos interpretativos que recuperan la cultura de la comunidad como parte del currículum escolar; 2) Prácticas experienciales, tales como: “... se hacen talleres de greda, coirón y mimbre en los propios talleres de artesanas, taller de gastronomía en hogares de abuelas de la comunidad" (AK, 4), favoreciendo interacciones sociales propias de la comunidad y 3) Prácticas relacionales inclusivas: "aquí todos somos amigos...todo lo hacemos para colaborarnos entre todos” (CD, Estudiante), "a mí me gusta que me incluyan en todos los talleres, en todos los juegos típicos” (CD, Estudiante), de esta forma se legitiman públicamente aspectos relacionales valora- 
dos por la comunidad; y 4) Prácticas de salud y sanación, expresados en: "talleres de yoga diario, taller de educación física y taller de salud y nutrición” (Az kintun 2), así se visibilizan prácticas focalizadas en el desarrollo individual del alumnado que reflejan el reconocimiento recíproco entre las interacciones que promueve la escuela y las de la comunidad en la que está inserta la escuela.

\subsubsection{Territorialidad escolar}

La comunidad campesina, previo a la conformación del aula comunitaria, constató que el espacio escolar era cerrado y privado, por lo que fue caracterizado como conocimiento exclusor, en tanto indicadores de menosprecio. Expresiones que grafican el menosprecio son: “...un lugar donde todas las actividades se realizaban en su interior y de forma privada entre docente y escolares, en total ausencia de otros actores de la comunidad” (AK, 2). Estos nodos fueron categorizados como formas de menosprecio, pues los ámbitos de injusticia, comprendían la territorialidad como privacidad, circunscripción a un único espacio e inmovilidad entre las personas y colectivos acotada a la institución escolar.

En cambio, la comunidad campesina, posterior a la conformación del aula comunitaria, constató que la territorialidad era entendida como creación de un espacio común y público para todo el colectivo, por lo que fue caracterizado como conocimiento transformador, y por consiguiente como indicador de reconocimiento. Algunos registros son: “... uso permanente de la escuela por parte de la comunidad para realizar festividades locales y nacionales, actividades sociales y vecinales, actividades artísticas y culturales” (AK,2),“...la escuela se manifiesta para la comunidad como un lugar común donde encontrarse, a celebrar, a resolver problemáticas, a renovar la cultura, a socializar, es decir, un lugar que les pertenece” (AK, 3), “...la comunidad como un espacio escolar... todos los espacios de la comunidad (hogares, campos, huertas, establos, cocinas, talleres de artesanía, museos, etc.), y otros (transporte escolar, vehículos particulares) se transforman en aulas" $(\mathrm{AK}, 1)$. Estos nodos se identifican como formas de reconocimiento, en tanto aspectos de justicia, expresados en la creación de un espacio escolar abierto a la comunidad, un espacio de expansión y difusión de las experiencias educativas que logra desplazar el territorio escolar hacia toda la comunidad. Además, cabe destacar la expansión de esta experiencia hacia otras escuelas de la comuna. Como resultado, se produce el efecto de reconocimiento, dado por una territorialidad fuertemente anclada a las tradiciones locales (campesinas), y ampliamente abierta a la novedad que aporta una escuela que se hace presente en todos los espacios posibles de ocupar.

\subsection{Comunidad minera. Menosprecio y reconocimiento en las dinámicas orga- nizativas}

\subsubsection{Articulación de redes}

La comunidad minera, previo a la conformación del aula comunitaria, constató la ausencia de redes entre personas e instituciones. Éste ámbito fue categorizado como conocimiento exclusor, por consiguiente, indicador de situaciones de menosprecio. Ejemplos que grafican el menosprecio son: “...aquí los apoderados, solo venían a las reuniones o cuando se les citaba por algo puntual... ni soñar ingresar apoderados o personas de otras instituciones a colaborar en los aprendizajes del aula, no era permitido" (CD, Docente); "antes no se podía entrar a la sala, solo para reuniones que citaba el colegio" (CD, Madre), así, se invisibilizaba a las organizaciones sociales e instituciones de la comunidad y de otros espacios que pudieran colaborar con la escuela. Al mismo tiempo, somete al estudiantado a patrones interpretativos exclusivos de la organización escolar, por el despojo de sus propias formas de organización como válidas para contribuir en la escuela.

En cambio, la comunidad minera, posterior a la conformación del aula comunitaria, constata la presencia de redes entre personas e instituciones, ámbito categorizado como conocimiento transformador, por consiguiente, insumo para identificar el reconocimiento. Ejemplos que grafican esto son: redes entre personas "...generación de redes entre docente, madres y abuelas; docente, equipos interdisciplinares; profesora, docentes universitarios; docente y voluntariado; docente y equipos de gestión; docente y alumnado, siendo la red más evidente la de las familias de los escolares con la docente" $(\mathrm{AK}, 2)$, redes institucionales "aparece sólo el gremio docente que actúa de 
forma indirecta en la experiencia" (AK,1), así se visibiliza una fuerte representación de personas que colaboran en la escuela, de esta forma, se rompe con la dominación de un solo modelo organizativo escolar, y se amplía a la diversidad de formas de organización que portan las personas que participan en las aulas comunitarias. Por su parte, las redes institucionales están escasamente representadas, por lo cual no es posible asegurar el reconocimiento en este ámbito.

\subsubsection{Formas de trabajo en el aula}

La comunidad minera, previo al aula comunitaria, constata que las formas de trabajo en el aula, consisten en clases frontales y expositivas con prácticas descontextualizadas y las categoriza como conocimiento exclusor, en tanto indicadores de menosprecio. Algunas voces que lo ejemplifican son: “...la única que mandaba aquí era la profesora, los niños tenían que escuchar no más” (CD, Madre); “...no se permitía enseñar la cultura nuestra, de la mina, de la feria, eso no se consideraba importante para ser enseñado en la escuela” (CD, Madre). Estos ámbitos fueron categorizados como formas de menosprecio, pues se observaba, la invisibilización del alumnado, la sujeción del mismo a la figura de poder y control del docente, el sometimiento interpretativo de los saberes curriculares oficiales impuestos como únicos al alumnado y la exclusión de la cultura minera como ámbito de interpretación curricular y el despojo de roles y prácticas de la cultura minera en la escuela.

En cambio, la comunidad minera, posterior a la conformación del aula comunitaria, constató un conjunto de prácticas que categoriza como conocimiento transformador, por tanto, indicadores de reconocimiento: 1) Prácticas propias de la cultura minera expresadas “...en la recuperación de literatura, leyendas e historias propias de la cultura minera y desde las voces de madres y abuelas” (AK, 1), evidencian la amplitud interpretativa que adquiere el trabajo escolar; 2) Prácticas de bienestar "...desayuno diario que se ofrece a las y los escolares, y la posibilidad de cada madre para compartir con sus hijos e hijas al interior del aula en el momento y tiempos que desee" (AK, 4) y 3) Prácticas lúdicas, expresadas en "el disfrute como base del aprendizaje que se persigue, aquí se encuentra una diversidad de juegos educativos y diversas actividades que incluyen mayoritariamente dramatizaciones" (AK, 3), dan cuenta de la visibilización de prácticas propias de la cultura que portan las madres que participan en la escuela y de las formas de expresión de las y los escolares; y 4) Prácticas relacionales inclusivas, entre otras: "se escucha la voz de todas las mamás, hacemos participar a los niños también para preguntarles qué les gustaría aprender, aunque son pequeñitos. La profesora nos hace participar y decidir sobre cómo educamos a los niños en las clases" (CD, Madre), de esta forma se legitima públicamente la participación de diversidad de personas en las decisiones escolares.

\subsubsection{Territorialidad escolar}

La comunidad minera, previo a la conformación del aula comunitaria, constata un espacio escolar cerrado y privado, que caracteriza como conocimiento exclusor, por tanto, indicador de menosprecio. Algunos registros que expresan esta condición son: “...el trabajo escolar estaba reducido al aula, a puerta cerrada, se consideraba que solo allí ocurre el aprendizaje" (CD, Docente), "la sala de clases era un espacio vetado para las mamás, no podíamos entrar" (CD, Madre). Estos ámbitos fueron categorizados como formas de menosprecio, pues la injusticia, comprendía la territorialidad como privacidad, circunscripción e inmovilidad acotada a la institución escolar.

En cambio, la comunidad minera, posterior a la conformación del aula comunitaria, constata que la territorialidad se entiende como creación de un espacio común y público para todo el colectivo, que caracteriza como conocimiento transformador, por tanto, indicador de reconocimiento. Ejemplos de ello, son: “...en el espacio del aula, se desarrollan festejos locales tradicionales, celebraciones colectivas por algún logro alcanzado, y también es un espacio de contención emocional tanto para escolares como para las madres que colaboran a diario en el aula." (AK, 3), "también es un espacio al que docentes de otras escuelas de la provincia vienen a formarse para transformar sus propias aulas (AK, 1). Estos nodos se identifican como formas de reconocimiento, en tanto aspectos de justicia, expresados en la creación de un espacio escolar de contención afectiva abierto a las familias de los y las escolares, un espacio de expansión y difusión de las experiencias educativas 
que suceden, que logra desplazar el territorio escolar de la institución a otras escuelas. Como resultado, se produce el efecto de reconocimiento, dado por una territorialidad ampliada que genera seguridad, pertenencia y movilización de las familias a la escuela y proyección de la experiencia a otras escuelas de la provincia.

\subsection{Comunidad mapuce. Menosprecio y reconocimiento en las dinámicas orga- nizativas}

\subsubsection{Articulación de redes}

La comunidad mapuce, previo a la conformación del aula comunitaria, constató la ausencia de redes entre personas e instituciones. Éste ámbito fue categorizado como conocimiento exclusor, por consiguiente, indicador de situaciones de menosprecio. Ejemplos que grafican el menosprecio son: “...la escuela estaba en manos de la Iglesia Católica y del Magisterio de La Araucanía, nosotros estábamos subordinados a ellos, por lo tanto, no había redes de colaboración entre nosotros, entre el lof [organización social del pueblo mapuce, compuesta por integrantes con parentesco familiar, vinculada a un territorio] y la escuela” (CD, Director escuela), “...no se permitía ninguna manifestación de nuestras formas de ser” (CD, Docente), así, la escuela invisibilizaba las formas de organización del pueblo mapuce y de cualquier otra institución que pudieran colaborar con la escuela, somete al estudiantado a patrones interpretativos únicos y occidentales y excluye las formas de organización de este pueblo como parte del proceso de formación en la escuela.

En cambio, la comunidad mapuce, posterior a la conformación del aula comunitaria, constata la presencia de redes entre personas e instituciones, ámbito categorizado como conocimiento transformador, por consiguiente, insumo para identificar el reconocimiento. Ejemplos que grafican el reconocimiento son: “...se han instaurado redes que reproducen la estructura sociopolítica del pueblo mapuce como parte del funcionamiento de la escuela, coordinadas por el lof, en que destacan tres figuras claves, kimces [personas mayores sabias que cuentan con gran respeto en la comunidad ya que representan la sabiduría histórica, cultural del pueblo mapuce], Logko [autoridad política del lof, en este caso también como autoridad docente, es el director de la escuela] y Maci [autoridad espiritual de la comunidad y curador de las enfermedades del espíritu]. Esta red es apoyada, por colaboraciones estratégicas [Docentes universitarios han sido claves en la elaboración de planes y programas] la cultura mapuce, e instituciones gubernamentales encargadas de aprobarlos]" (AK, 4). De esta forma, se observa el reconocimiento porque se visibiliza la organización sociopolítica propia del pueblo mapuce, se rompe con la dominación del modelo escolar occidental de organización, en tanto patrón hegemónico de interpretación, y en su reemplazo, se impone la organización propia del pueblo mapuce. Por su parte, las redes institucionales externas al pueblo mapuce son incorporadas de forma estratégica, por lo cual no es posible asegurar el reconocimiento en este ámbito.

\subsubsection{Formas de trabajo en el aula}

La comunidad mapuce, previo al aula comunitaria, identifica las formas de trabajo en el aula, centradas en clases frontales y expositivas con prácticas descontextualizadas y las categoriza como conocimiento exclusor. Algunas voces que lo ejemplifican son, "cuando la escuela estaba a cargo de la Iglesia, sólo el profesor era el que hablaba, él no era mapuce...estaba prohibido hablar nuestra lengua, contar nuestra cultura” (CD, Docente) “...todos tenían que hablar el mismo idioma, el español y todos tenían que aprender la historia de Chile, de Europa, de América” (CD, Director escuela). Estos ámbitos fueron categorizados como formas de menosprecio, pues se observaba, la invisibilización del alumnado y la sujeción del mismo a la figura de poder y control del docente, el sometimiento interpretativo de los saberes curriculares oficiales occidentales en detrimento de los propios del pueblo mapuce como ámbito de interpretación curricular y el despojo de roles y prácticas propias de la cultura mapuce en la escuela.

En cambio, la comunidad mapuce, posterior a la conformación del aula comunitaria, constató un conjunto de prácticas que categoriza como conocimiento transformador, por tanto, indicadores de reconocimiento: 1) Ceremonias ancestrales, tales como, “...jejipun [Ceremonia de agradecimiento 
al mapu -territorio-, a la naturaleza, y petición de tener un buen día, busca prepararse integralmente para comenzar algo] y guijatun [Rogativa como una forma de agradecimiento o petición]" $(\mathrm{AK}, 1) ; 2)$ Parlamentos, tales como, “...xawun [Asambleas, que consiste en diálogos ampliados con participación de la familia para tratar diversos temas], y nuxan [Diálogo en profundidad respecto a algo entre dos o más personas]" (AK, 4);3) Prácticas ancestrales, expresados en que "incorporan actividades que reproducen artesanías (trabajar la lana, las hierbas, el barro) y cultivos (papas, quinua, etc.), y la recuperación y revalorización de árboles nativos considerados sagrados, además que permiten el equilibrio entre el ce [ser] y el mapu [territorio]" (Az kintun 3), evidencian el reconocimiento en la incorporación del patrimonio interpretativo de la cultura mapuce, las manifestaciones culturales públicas y su visibilización.

\subsubsection{Territorialidad escolar}

La comunidad mapuce, previo a la conformación del aula comunitaria, constató un espacio escolar cerrado y privado, el que fue caracterizado como conocimiento exclusor, por tanto, indicador de menosprecio. Ejemplos son: “...la escuela estaba cerrada... inserta en la comunidad, pero cerrada...Una escuela al servicio de la evangelización y la visión occidental” (CD, Director escuela). Estos nodos fueron categorizados como formas de menosprecio, pues los ámbitos de injusticia, comprenden la territorialidad como privacidad, circunscripción e inmovilidad acotada a la institución escolar.

En cambio, la comunidad mapuce, posterior a la conformación del aula comunitaria, constató que la territorialidad era entendida como un espacio político y social mapuce, lo que caracterizó como conocimiento transformador, y por consiguiente como indicador de reconocimiento. Algunos registros, son: “...la lucha política se disputa tanto en el espacio geográfico [recuperación de la escuela] como en el espacio simbólico que busca posicionar su cultura, lengua y cosmovisión [a través de los planes y programas propios], además de mantener en el currículum escolar una parte de los saberes del currículo nacional, a fin de preparar a los/las escolares también en la cultura chilena” (AK, 3), “...recuperación de la circularidad [recogiendo el concepto de ciclo de la cultura mapuce] en la organización las aulas de la escuela, en las rukas y en la naturaleza [bosques, mar, lago, etc.]"(AK, 1), de esta forma, se identifican formas de reconocimiento, en tanto aspectos de justicia, expresados en la creación de un espacio común que visibiliza el lof, que logra instaurar su propio patrón interpretativo de acuerdo a su cosmovisión y la recuperación geográfica y simbólica del lof públicamente reconocida. Por otra parte, esta experiencia, ha logrado expandir sus prácticas territoriales al difundir a otras escuelas mapuce de la región en la que se ubica, “... mostrar esto a otros territorios [experiencia pedagógica], a la Academia” (AK, 2). “...la escuela realiza visitas a otras escuelas mapuce en la que enseña su experiencia y aprende de esas escuelas” (AK, 3). Como resultado, se produce el efecto de reconocimiento, a través de una territorialidad que ofrece seguridad en tanto espacio que le pertenece a todo el lof, que debe ser ocupado por sus miembros y que les permite la movilización social que fortalece su lucha política y cultural, proyectando el proceso de recuperación a otras comunidades mapuce.

\section{Discusión y conclusiones}

Un primer eje de los hallazgos, que cabe discutir es que, más allá de las especificidades puntuales de cada contexto, a través de las dinámicas organizativas de las aulas comunitarias con pedagogía dialógica, estas comunidades escolares logran avanzar en ámbitos de justicia social desde el reconocimiento (Cuadro 2). 


\begin{tabular}{|c|c|c|c|c|}
\hline & Injusticia/ & \multicolumn{3}{|c|}{ Justicia/Reconocimiento } \\
\hline & $\begin{array}{l}\text { Aspectos Comunes En } \\
\text { Las Tres Aulas }\end{array}$ & Aula Campesina & Aula Minera & Aula Mapuce \\
\hline \multirow{2}{*}{ 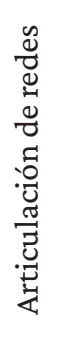 } & $\begin{array}{l}\text { Ausencia de redes (invi- } \\
\text { sibilización de personas } \\
\text { externas a la escuela) } \\
\text { Ausencia de redes con }\end{array}$ & $\begin{array}{l}\text { Redes con personas } \\
\text { (abuelas/os, madres, } \\
\text { agricultores, artesa- } \\
\text { nas) }\end{array}$ & \multirow{2}{*}{$\begin{array}{l}\text { Redes con personas } \\
\text { (madres y abuelas, } \\
\text { equipo de gestión, } \\
\text { equipos interdiscipli- } \\
\text { nares) }\end{array}$} & $\begin{array}{l}\text { Recomposición de la } \\
\text { estructura sociopolíti- } \\
\text { ca del pueblo mapuce } \\
\text { (kimces, Logko y Maci) }\end{array}$ \\
\hline & $\begin{array}{l}\text { instituciones (invisibili- } \\
\text { zación de agencias) }\end{array}$ & $\begin{array}{l}\text { Redes con instituciones } \\
\text { (museos, municipios, } \\
\text { microcentros escolares, } \\
\text { etc.) }\end{array}$ & & $\begin{array}{l}\text { Colaboraciones estra- } \\
\text { tégicas (con docentes } \\
\text { universitarios, institu- } \\
\text { ciones gubernamen- } \\
\text { tales) }\end{array}$ \\
\hline \multirow{4}{*}{ 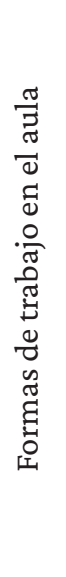 } & $\begin{array}{l}\text { Basadas en relaciones de } \\
\text { poder (clases frontales) }\end{array}$ & \multirow{4}{*}{$\begin{array}{l}\text { Prácticas propias de } \\
\text { la cultura campesina } \\
\text { (cultivo de la tierra, } \\
\text { cuidado de animales, } \\
\text { etc.) incluidas en el } \\
\text { currículum escolar. } \\
\text { Prácticas experien- } \\
\text { ciales (artesanía y } \\
\text { gastronomía local) } \\
\text { incluidas en el currícu- } \\
\text { lum escolar. }\end{array}$} & \multirow{3}{*}{$\begin{array}{l}\text { Prácticas propias de } \\
\text { la cultura minera } \\
\text { (literatura, cuentos, } \\
\text { leyendas e historias } \\
\text { de la cultura minera) } \\
\text { incluidas en el currí- } \\
\text { culum escolar } \\
\text { Prácticas lúdicas } \\
\text { (juegos educativos y } \\
\text { dramatizaciones) }\end{array}$} & $\begin{array}{l}\text { Incorporación de ce- } \\
\text { remonias ancestrales } \\
\text { (jejipun, guijatun) }\end{array}$ \\
\hline & $\begin{array}{l}\text { contextualizadas de la } \\
\text { cultura del alumnado. }\end{array}$ & & & $\begin{array}{l}\text { Incorporación de } \\
\text { parlamentos (xawun, } \\
\text { nuxam) }\end{array}$ \\
\hline & & & & $\begin{array}{l}\text { Incorporación de } \\
\text { prácticas ancestrales } \\
\text { (artesanías y cultivos } \\
\text { propios) }\end{array}$ \\
\hline & & & $\begin{array}{l}\text { Prácticas relacionales } \\
\text { inclusivas (madres, } \\
\text { abuelas y escolares } \\
\text { participan en el currí- } \\
\text { culum escolar) }\end{array}$ & \\
\hline \multirow{6}{*}{ 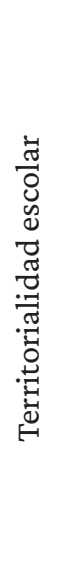 } & \multirow{6}{*}{$\begin{array}{l}\text { La escuela y el aula } \\
\text { como un espacio cerra- } \\
\text { do y privado (fragmen- } \\
\text { tación entre escuela y } \\
\text { comunidad) } \\
\text { Docente y estudiantes } \\
\text { como únicos actores del } \\
\text { proceso educativo (de- } \\
\text { sintegración social) }\end{array}$} & \multirow{6}{*}{$\begin{array}{l}\text { Escuela abierta a la } \\
\text { comunidad } \\
\text { Escuela como espa- } \\
\text { cio común y público } \\
\text { (tradiciones locales, } \\
\text { deliberaciones conjun- } \\
\text { tas) } \\
\text { La comunidad como un } \\
\text { espacio escolar (huer- } \\
\text { tos, cocinas, establos, } \\
\text { talleres, etc.) }\end{array}$} & \multirow{6}{*}{$\begin{array}{l}\text { Creación de espacio } \\
\text { común y público } \\
\text { (tradiciones locales, } \\
\text { contención emocio- } \\
\text { nal para escolares y } \\
\text { madres) } \\
\text { Espacio de formación } \\
\text { para otras escuelas } \\
\text { (docentes de otras } \\
\text { escuelas vienen a } \\
\text { formarse en esta aula } \\
\text { comunitaria) }\end{array}$} & $\begin{array}{l}\text { Recuperación de la } \\
\text { escuela por parte de la } \\
\text { comunidad mapuce }\end{array}$ \\
\hline & & & & $\begin{array}{l}\text { Espacio de lucha } \\
\text { política que disputa }\end{array}$ \\
\hline & & & & el espacio geográfi- \\
\hline & & & & $\begin{array}{l}\text { co y simbólico para } \\
\text { posicionar la cultura y } \\
\text { lengua mapuce }\end{array}$ \\
\hline & & & & $\begin{array}{l}\text { Recuperación de la cir- } \\
\text { cularidad en las aulas, } \\
\text { ruka y naturaleza }\end{array}$ \\
\hline & & & & $\begin{array}{l}\text { Espacio de difusión } \\
\text { para otras escuelas de } \\
\text { la región. }\end{array}$ \\
\hline
\end{tabular}

Primero, a través de la articulación de redes, las personas logran corporeizarse/visibilizarse en los distintos espacios formativos, es decir, en el estar presente para las demás, expresarse libremente al interior del colectivo, impactando así la construcción de autoconfianza, como también, logran estima social al ser considerados integrantes legítimos de un proyecto común (Honneth, 1997, 2011). Con lo mismo, rompen con la invisibilización previa de la cultura que portan, con ello avanzan en estatus frente a la cultura hegemónica oficial (Fraser, 2008, 2018). Segundo, a través de las formas de trabajo en el aula, las personas logran participar en las decisiones educativas y con ello incluir sus propios patrones culturales como parte del currículum escolar, lo que se correspondería con la igualdad de trato en términos de Honneth $(2011,2018)$, y con la paridad participativa necesaria para la igualdad de estatus cultural en palabras de Fraser $(2008,2018)$. Con esto, se revela que el reconocimiento que se busca, no es la mantención del patrón cultural de forma aislada (minera, mapuce, campesina) 
como lo plantea Taylor (1993), sino una incorporación del mismo en el currículum oficial. Y tercero, la territorialidad escolar, construida como un espacio común (escuela-comunidad) que rompe con la privacidad del territorio produciendo seguridad y protección en las interacciones sociales entre las personas, impactando en la generación de autoconfianza, por una parte, y por otra, estima social, pues crea un espacio bidireccional entre el territorio escolar legitimado por los aportes de cada uno son valiosos y reconocidos públicamente en ambos espacios (Honneth, 1997, 2018). Estos hallazgos permiten concluir, que la justicia social de reconocimiento que alcanzan estos colectivos que conforman las aulas comunitarias, encuentran relación con las propuestas de Honneth y Fraser, no así con la de Taylor. No obstante, se requiere seguir investigando para profundizar al respecto.

Un segundo eje de discusión es que, se constata la hipótesis sobre que los sentimientos de injusticia o formas de menosprecio percibidas por las y los integrantes de los colectivos en cada contexto (minero, campesino, mapuce) resulta ser el gatillador que canaliza las luchas para alcanzar justicia a través de los proyectos de aulas comunitarias, cuestiones que se sospechaban en investigaciones previas sobre estas aulas (Ferrada, 2020). Este hallazgo encuentra relación con la afirmación que "establece un vínculo entre las causas sociales de los sentimientos generalizados de injusticia y los objetivos normativos de los movimientos emancipadores” (Honneth, 2018, p. 91). De esta forma, también es posible concluir que los colectivos agenciadores de las aulas comunitarias con pedagogía dialógica Enlazando Mundos constituyen movimientos emancipadores de reconocimiento.

\section{Referencias}

Abd, N. (2016). Dialogic pedagogy and educating preservice teachers for critical multiculturalism. Sage Open, 1, 1-13. https://doi.org/10.1177/2158244016628592

Álvarez, J. (2000). Organización escolar: Bases científicas para el desarrollo de las instituciones educativas. Revista Española de Pedagogía, 58(215), 174-177.

Astorga, B. (2018). Desde la pedagógica dialógica enlazando mundos, aportes para una didáctica dialógica en la enseñanza de la lengua [Tesis doctoral, Universidad Academia Humanismo Cristiano]. Archivo de la Universidad Academia Humanismo Crisiano.

Bakhtin, M. (1991). Dialogic imagination: Four essays. University Of Texas Press.

Bengoa, J. (2009). La comunidad fragmentada. Catalonia.

Donoso, C. (2003). Charles Taylor: Una crítica comunitaria al liberalismo político. Polis. Revista Latinoamericana, 6, $1-22$.

Ferrada, D. y Del Pino, M. (2018). Dialogic-kishu kimkelay ta che educational research: Participatory action research. Educational Action Research, 26(4), 533-549. https://doi.org/10.1080/09650792.2017.1379422

Ferrada, D. (2012). Construyendo escuela, compartiendo esperanzas. La experiencia del proyecto enlazando mundos. Ril Editores.

Ferrada, D. (2017). La investigación participativa dialógica. En S. Redón Pantorra y J. Rasco Angulo (Eds.), Metodología cualitativa en educación (pp.187-201). Miño y Dávila.

Ferrada, D. (2020). Dialogic pedagogy linking worlds: Participatory community classrooms. Pedagogy, Culture and Society, 28(1), 131-146. https://doi.org/10.1080/14681366.2019.1615534

Ferrada, D., Villena, A., Catriquir, D., Pozo, G., Turra, O., Schilling, C. y Del Pino, M. (2014). Investigación dialógica-kishu kimkelay ta che en educación. Revista REXE, 13(26), 33-50.

Fraser, N. (2008). Escalas de justicia. Herder.

Fraser, N. (2018). La justicia social en la era de la política de la identidad: Redistribución, reconocimiento y participación. En N. Fraser y A. Honneth (Eds.), ¿Redistribución o reconocimiento? (pp. 17-88). Morata.

Freire, P. y Shor, I. (2008). Miedo y osadía. Siglo XXI.

Freire, P. (1970). Pedagogía del oprimido. Tierra Nueva. 
Gayá Wicks, P. y Reason, P (2009). Initiating action research: challenges and paradoxes of opening communicative space. Action Research, 7(3), 243-262. https://doi.org/10.1177/1476750309336715

George-Nascimento, J. (2015). La didáctica dialógica: Construcción intersubjetiva de la didáctica enlazando mundos con inteligencias múltiples, por una comunidad de investigación en un aula combinada de escuela básica rural [Tesis de maestría, Universidad Católica de la Santísima Concepción]. Archivo de la Universidad Católica de la Santísima Concepción.

Guba, E. y Lincoln, Y. (2012). Controversias paradigmáticas, contradicciones y confluencias emergentes. En N. Denzin e Y. Lincoln (Eds.), Paradigmas y perspectivas en disputa. (pp. 38-78). Gedisa

Habermas, J. (1987). Teoría de la acción comunicativa. Taurus.

Heron, J. y Reason, P. (1997). A participatory inquiry paradigm. Qualitative Inquiry, 3(3), 274-294. https://doi.org/10.1177/107780049700300302

Herrera, J. (2016). La relación escuela-comunidad: Un análisis desde la teoría de sistemas a nueve experiencias de América Latina. Revista Interamericana de educación, pedagogía y Estudios Interculturales, 9(1), 11-33. https://doi.org/10.15332/s1657-107X.2016.0001.01

Honneth, A. (1997). La lucha por el reconocimiento. Por una gramática moral de los conflictos sociales. Crítica.

Honneth, A. (2011). La sociedad del desprecio. Editorial Trota.

Honneth, A. (2019). Reconocimiento. Una historia de las ideas europea. Akal.

Honneth. A. (2018). Redistribución como reconocimiento. Respuesta a Nancy Fraser. En N. Fraser y A. Honneth (Eds.), ¿Redistribución o reconocimiento? (89-148). Morata.

INE. (2020). Instituto Nacional de Estadísticas de Chile. INE.

JUNAEB. (2020). Junta nacional de auxilio escolar y becas. Prioridades 2020 con IVE SINAE básica media y comunal. JUNAEB.

Lagos, C. (2015). El programa de educación intercultural bilingüe y sus resultados ¿Perpetuando la discriminación. Pensamiento Educativo, 52(1), 84-94.

López, A. (2005). La organización del espacio en los centros educativos: un factor determinante para el cambio de las estructuras organizativas. Bordón, 57(4), 519-533.

Oliva, M. A. (2008). Política educativa y profundización de la desigualdad en Cile. Estudios pedagógicos, 34(2), 207 226. https://doi.org/10.4067/S0718-07052008000200013

Taylor, C. (1993). El multiculturalismo y la política del reconocimiento. Fondo de Cultura Económica.

Vázquez, S. (2008). Axel Honneth, disrespect. The normative foundations of critical theory. Foro Interno, 8, 167-247.

Velasco, J.A. y Alonso de González, L. (2008). Sobre la teoría de la educación dialógica. Educere, 12(42), 461-470.

Velásquez, M. T., Novoa, M. y Mayorga, M. (2006). La organización escolar: Punto de partida de la evaluación de los docentes. Innovar: Revista de Ciencias Administrativas y Sociales, 16(28), 93-110

Ward, I. (1994). Literacy, ideology, and dialogue towards a dialogic pedagogy. State University of New York Press.

Williamson, G. y Flores, F. (2015). Estado del arte de la educación intercultural bilingüe en Chile, 1990-2013. Ediciones Universidad de la Frontera.

\section{Agradecimientos}

Este trabajo contó con el apoyo del Proyecto FONDECYT REGULAR N1180238. 


\section{Breve CV de los/as autores/as}

\section{Donatila Ferrada}

Profesora Titular de la Universidad Católica del Maule. Doctora en Filosofía, Universidad de Valladolid, España. Magister en Educación, Universidad Metropolitana de Ciencias de la Educación, Chile. Directora del Centro de Investigación en Educación para la Justicia Social (CIEJUS). Investigadora responsable en numerosos proyectos de investigación competitiva, entre ellos, Proyecto Fondecyt Regular 1180238: Pedagogía dialógica enlazando mundos: experiencias de aulas comunitarias con justicia social. Autora de numerosos artículos científicos en revistas indexadas de corriente principal y autora de libros y capítulos de libros. Email: dferrada@ucm.cl

ORCID ID: https://orcid.org/0000-0003-0942-4320

\section{Miguel Del Pino}

Profesor Adjunto de la Universidad Católica del Maule. Doctor en Ciencias de la Educación (Universidad Nacional de Cuyo, Argentina). Es miembro del Centro de Investigación en Educación para la Justicia Social, CIEJUS; y Centro de Investigación en Estudios Avanzados del Maule, CIEAM. Actualmente es Investigador Responsable de Proyecto Fondecyt Iniciación 11180316, y Co-Investigador Proyecto Fondecyt Regular 1180238. Ha publicado artículos en revistas indexadas y de corriente principal. Su línea de investigación es Pedagogía dialógica, Evaluación educativa y justicia social. Email: mdelpino@ucm.cl

ORCID ID: https://orcid.org/0000-0003-3379-3994 